Article

\title{
Evaluation of Mobile Heat Treatment System for Treating In-Field HLB-Affected Trees by Analyzing Survival Rate of Surrogate Bacteria
}

\author{
Shirin Ghatrehsamani ${ }^{1, *}$, Eva Czarnecka ${ }^{2}$, F. Lance Verner ${ }^{2}$, William B. Gurley ${ }^{2}$, Reza Ehsani ${ }^{3}$ \\ and Yiannis Ampatzidis 1,*(D) \\ 1 Agricultural and Biological Engineering Department, Southwest Florida Research and Education Center, \\ University of Florida, 2685 FL-29, Immokalee, FL 34142, USA \\ 2 Department of Microbiology and Cell Science, Program of Plant Molecular and Cellular Biology, \\ University of Florida, Gainesville, FL 32611, USA; evaczar@ufl.edu (E.C.); lance4uf@ufl.edu (F.L.V.); \\ wgurley@ufl.edu (W.B.G.) \\ 3 Mechanical Engineering Department, University of California, Merced, CA 95343, USA; \\ rehsani@ucmerced.edu \\ * Correspondence: sh.samani@ufl.edu (S.G.); i.ampatzidis@ufl.edu (Y.A.)
}

Received: 8 August 2019; Accepted: 10 September 2019; Published: 12 September 2019

\begin{abstract}
Huanglongbing (HLB or citrus greening) is a disease caused by an insect-transmitted bacterial pathogen Candidatus Liberibacter asiaticus (CLas). Thermotherapy has been successfully used by others to reduce the population of CLas bacteria in HLB-affected citrus trees under greenhouse studies. Thermotherapy is the application of heat as a strategy to reduce the adverse economic impact of certain pests and diseases. CLas is a fastidious, non-cultivable organism. The high variance in CLas titers in canopy samples together with this lack of cultivability makes it impossible to use classical bacteriological techniques to measure the viability either before or after treatments. Therefore, we used the survival rates of a surrogate bacterium, Klebsiella oxytoca, in order to evaluate the effectiveness of a mobile thermotherapy delivery system developed for in-field treatment of HLB-affected trees. K. oxytoca is a Gram-negative, rod-shaped bacterium that was originally isolated from soil and has been used in the development of industrial applications related to ethanol fuel production. It served as a biologically-based sensor of temperature stress (biosensor) in this study. Thermocouples and biosensor packets (plastic cups with suspended small snap-top tubes) containing the K. oxytoca were attached to an HLB-affected citrus tree and their canopy locations mapped. The mobile thermotherapy treatment hood covered the canopy of the HLB-affected tree. Then, steam and hot water were injected through nozzles inside of the hood to increase the temperature of the tree canopy. A standard temperature-time combination of $54^{\circ} \mathrm{C}$ for $90 \mathrm{~s}$ was chosen based on preliminary studies where heat treatment parameters caused a significant reduction in CLas populations without inflicting permanent damage to the tree. The survival ratio of the K. oxytoca in the biosensor packets was found to range from complete elimination to $5 \%$ with treatments of $250 \mathrm{~s}$ and a maximum temperature of $54^{\circ} \mathrm{C}$.
\end{abstract}

Keywords: Huanglongbing; thermotherapy; biosensor; survivability; heat distribution

\section{Introduction}

Effective plant disease control is critical to the reliable production of food and could potentially result in substantial reductions in agricultural use of water, land, fuel, and other inputs. Two main methods are used in treating diseased plant parts and whole plants: Chemical and non-chemical. There is an effort in modern agricultural practices to reduce the use of chemicals as nutritional supplements or in pathogen control, especially for organic products. Thermotherapy provides a viable 
alternative to chemically-based pathogen control. In practice, thermotherapy approaches utilize either dry or wet heat, including the application of steam, hot water, or both a combination of them.

The challenge in the thermotherapy approach is finding the best combination of time and temperature that maximizes reduction in pathogen survival while minimizing the damaging effect to the plant $[1,2]$. An underlying assumption justifying the thermotherapy approach to pathogen control is that the target pathogen is more sensitive to high temperature stress than the plant.

Thermotherapy has been successfully utilized for several decades as a pathogen control strategy with greenhouse-grown plants and seeds, as well as with fruits from field-grown crops [1]. There are three main techniques of applying heat as treatment for plant materials: (1) Soaking in hot water, (2) hot air, and (3) vapor heat treatment. The main goal of thermotherapy is to provide a nonchemical method to reduce or eliminate pathogen damage [1,3]. Heat treatments have been developed to control damage in both greenhouse and controlled environments but seldom under field conditions. Generally, this approach has been most successful with certain plant viruses. Dry heat and hot water treatments have long been known to be useful in controlling yellow peach virus as well as other chlorotic viral diseases [4]. More recently, thermotherapy was effectively employed for inactivating citrus tristeza virus in budwood and preventing citrus quick decline disease [5-7]. There are also examples where thermotherapy approaches have provided effective treatments for bacterial plant pathogens in greenhouse or laboratory settings in various crop plants such as barley [3], cotton [8], cucumber [9], rice [10], tomato [11], and tobacco [12]. For sugarcane, thermotherapy is conducted in processing facilities in the form of aerated steam treatment (AST) or hot water treatment. It remains an effective protocol in propagation and has been utilized to drastically reduce the number of infected sets in the case of ratoon stunting disease (Leifsonia xyli subsp. xyli formerly Clavibacter xyli subsp. xyli) $[13,14]$ or, in some cases, eliminate grassy shoot disease (Candidatus Phytoplasma) [15]. The food industry has a long history of using heat treatments to effectively eliminate human pathogens such as Listeria monocytogenes, Salmonella, enteropathogenic Escherichia coli, and the spores of non-proteolytic strains of Clostridium botulinum and Bacillus cereus [16-19]. However, when dealing with propagation materials or other perishable plant parts, thermotherapy can show a range of effectiveness depending on the pathogen, the method of delivery, and the part of the plant treated. In its application to reduce pathogen populations, a balance must be achieved between the benefits of pathogen control and the potentially detrimental effects of elevated temperatures on the plant or plant materials. An example where the consideration of these two competing parameters is critical can be found in heat treatment regimens developed for the large seeds of legumes such as peas, soybeans, or beans [20].

Previous studies have established that ' $\mathrm{Ca}$. L. asiaticus' is relatively heat-tolerant with growth adept at temperatures up to $35^{\circ} \mathrm{C}[21,22]$. However, Chinese scientists have long known that relatively short heat treatments at $49-50{ }^{\circ} \mathrm{C}$ on budwood and seedlings can be an effective method of greatly reducing or eliminating the disease symptoms of huanglongbing (HLB)-affected citrus [23]. In efforts to reduce damage to the potted seedlings, Fan et al. [24] used short, repetitive exposures of $4 \mathrm{~h}$ to temperatures of 45 and $48^{\circ} \mathrm{C}$ over a period of three weeks. They obtained significant reductions in CLas titers that, as determined by PCR, were significantly reduced, with mature leaves showing reductions by a little over one half to decreases above $90 \%$ in new flushes (in eight weeks post-treatment). In experiments by Hoffman et al. [2] under controlled conditions, lower treatment temperatures of 40 and $42{ }^{\circ} \mathrm{C}$, coupled with longer exposure times of from seven to ten days, resulted in complete elimination of CLas for as long as two years. However, the application of heat treatments under field conditions has proven more problematic. For example, a study utilizing solar heating, using plastic enclosures, demonstrated drastic reductions in CLas titers determined by PCR for 18-36 months post treatment; however, the bacteria were not eliminated by the treatment and returned to pretreatment levels in as soon as three years [25].

As a result of the general conclusion supported by previous studies that conditions exist where CLas titers can be severely reduced or eliminated by exposure to elevated temperatures without inflicting lasting harm on the plant, we have developed a mobile thermotherapy system based on steam and hot water application for field evaluation and use [26,27]. In this paper, the effectiveness in killing 
a surrogate bacterium for CLas (Klebsiella oxytoca) was monitored by determining the survival ratios for cultures before and after treatment. Small aliquots of $K$. oxytoca were placed in thin-walled PCR tubes (a biosensor apparatus), distributed to various locations within the canopy of the test tree, and their positions were mapped in order to construct a survivability profile of the canopy after heat treatment.

\section{Materials and Methods}

\subsection{Mobile Heat Treatment System}

The mobile heat treatment system (MHTS) included a tree canopy cover (hood) and components to produce a heat source, namely a water tank and pump with two filters, a generator, a steamer, a pressure washer, and a water softener (passage through resin that removes excess calcium and magnesium ions), as seen in Figure 1a. A detailed MHTS description was presented by Ghatrehsamani et al. [27]. Figure $1 \mathrm{~b}$ shows the workflow of the heat treatment process. Each treatment process includes three main phases: (1) pre-treatment, (2) treatment and (3) post-treatment [27]. The process started when the MHTS approached the target tree, and the canopy cover enveloped the tree in the "pre-treatment" step. Then in the "treatment" step, steam was applied, and the temperature was monitored. When the temperature reached the target temperature of $54^{\circ} \mathrm{C}$, the operator stopped the heating system and kept the tree covered for $90 \mathrm{~s}$. After that, the tree was uncovered, and the "post-treatment" step was complete.

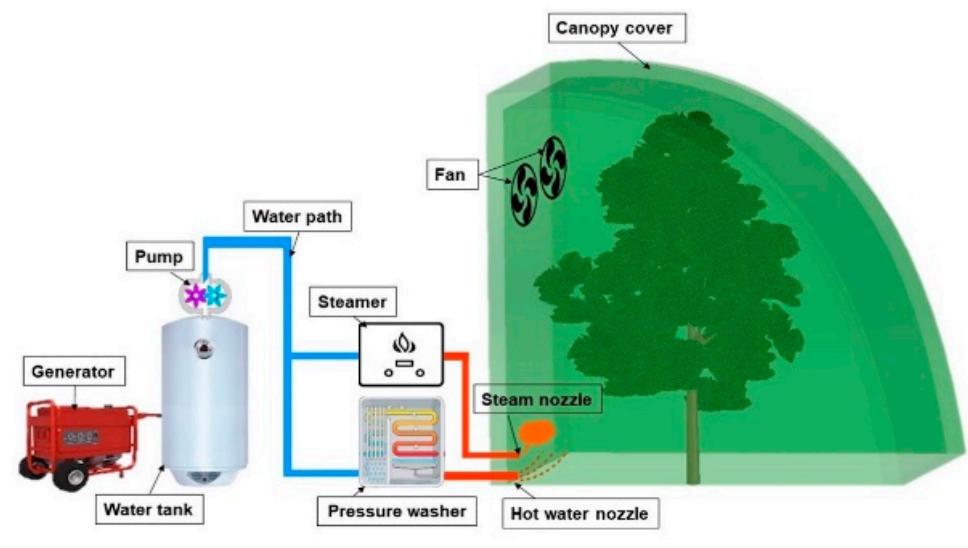

a.

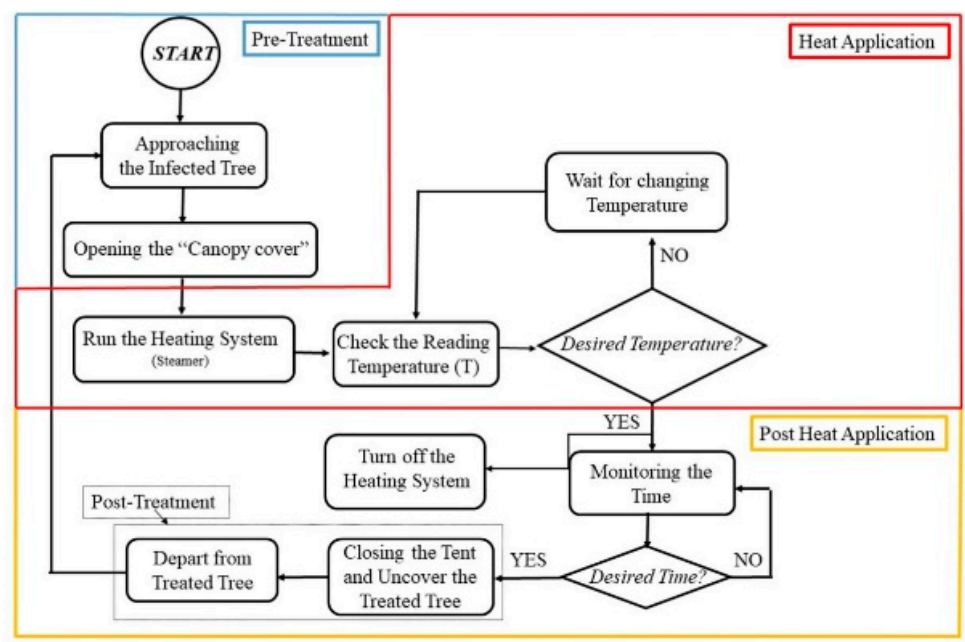

b.

Figure 1. a. Schematic diagram of the mobile heat treatment system (MHTS) system and its components. b. Flowchart of the heat treatment process and its three main parts. 


\subsection{Temperature Acquisition System}

Twelve K-type thermocouples with $\pm 0.2{ }^{\circ} \mathrm{C}$ accuracy were applied to monitor the temperature [27]. Thermocouples were installed in three different zones of the test tree (Figure 2a). Thermocouples 1-4 were specifically positioned on the tree trunk (Zone 1), whiles thermocouples 5-12 were placed in the canopy of the citrus tree; four of them were in the middle canopy (Zone 2), and four of them were in the upper canopy (Zone 3) (Figure 2a). The sensors were calibrated by utilizing a combination of water and ice, which resulted in $0{ }^{\circ} \mathrm{C}$ temperature and was so called "the ice-water method" [28]. The OMEGA RXL12SD (OMEGA RXL12SD, Omega Engineering, Stamford, CT, USA) (a 12-channel temperature monitor recorder by $1 \mathrm{~Hz}$ logging frequency) recorded the measured temperature, and data were stored on an SD card. The location of the thermocouples is presented in Table 1. A MATLAB (V5 R2018b, MathWorks Inc, Natick, MA, USA) script was developed to create the 3D heat distribution maps.

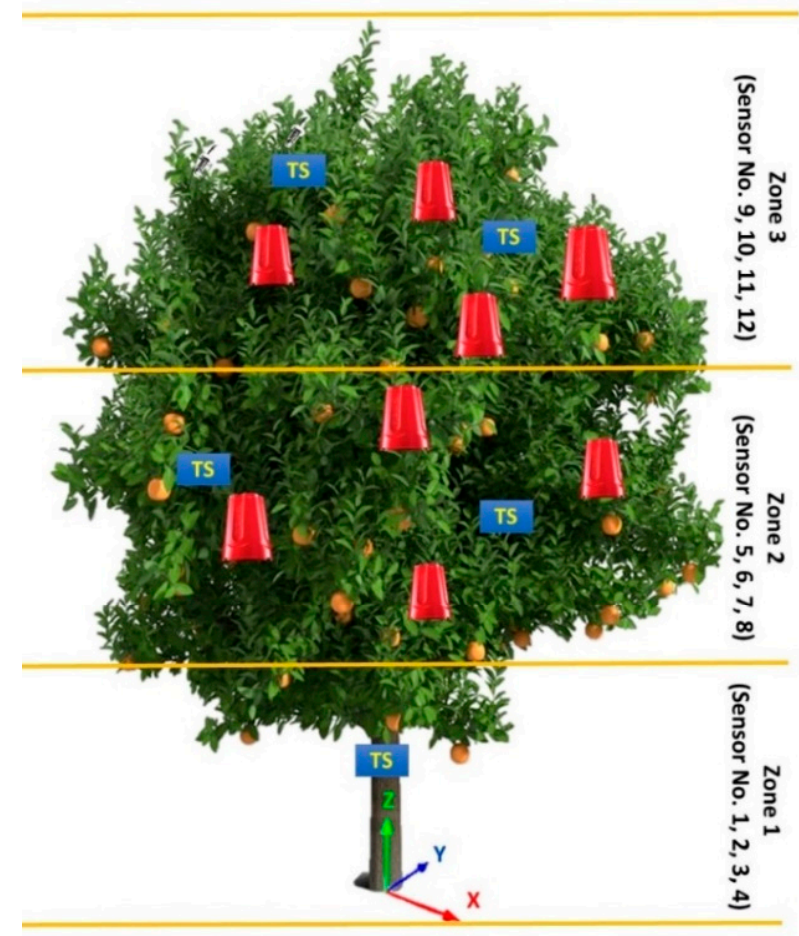

a.

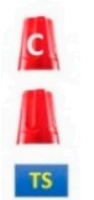

PCR cup included control biosensor

PCR cup included biosensor

K-type thermal sensor

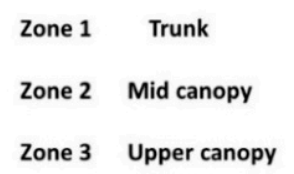

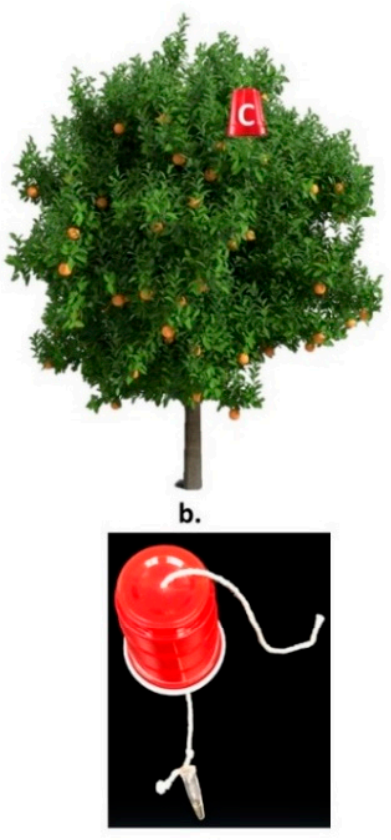

c.

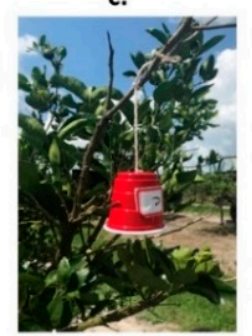

d.

Figure 2. a. Schematic diagram of the thermal sensors and biosensors (red cups with cultures) positioning within the three zones (six of the thermocouples are visible in Figure $2 \mathrm{a}$, and six of them are installed in the other side of the tree and not visible in Figure 2a.). b. Schematic diagram and location of control biosensor. c. Biosensor culture attached to the cup prior to installation on the target tree. d. Control biosensor installed on a non-treated tree. 
Table 1. Thermal sensor coordinates (The center of the tree trunk is considered as the origin of the coordinates, as shown in Figure 2a.).

\begin{tabular}{ccccc}
\hline & Thermal Sensor No. & $\boldsymbol{4}$ & Coordinate (cm) \\
& 1 & 0 & $y$ & $z$ \\
\hline \multirow{3}{*}{ Zone 1 } & 2 & 0 & 0 & 30.50 \\
& 3 & 0 & 0 & 68.25 \\
& 4 & 0 & 0 & 91.45 \\
\hline \multirow{3}{*}{ Zone 2 } & 5 & -101.60 & -81.28 & 114.30 \\
& 6 & -43.18 & 76.20 & 106.68 \\
& 7 & 45.72 & 12.70 & 119.38 \\
Zone 3 & 8 & -29.94 & -12.70 & 109.22 \\
& 9 & 7.62 & -83.82 & 152.40 \\
& 10 & -53.34 & 17.78 & 172.72 \\
& 11 & 17.78 & 25.40 & 182.88 \\
& 12 & -88.90 & -53.34 & 170.18 \\
\hline
\end{tabular}

\subsection{Biosensors}

Due to environmental concerns related to the use of ' $\mathrm{Ca}$. Liberibacter crescens', a close relative of CLas, Klebsiella oxytoca M5a1 was chosen as a surrogate bacteria for 'Ca. Liberibacter asiaticus' to develop a model of bacterial survivability in the canopy of a field-grown citrus tree [29]. K. oxytoca M5a1 was routinely grown in a liquid Luria broth medium with $100 \mu \mathrm{g} / \mathrm{mL}$ of streptomycin (LB and Strep 100) $[29,30]$. Heat survivability analyses were conducted by spreading serial dilutions on square LB and Strep 100 agar (15 g/L) plates (BP1423-500, Fisher Scientific, Pittsburgh, PA, USA). For the steam treatment experiments, one isolated colony of $K$. oxytoca was grown in $3 \mathrm{~mL}$ of the LB and Strep 100 at $37^{\circ} \mathrm{C}$ with shaking until an OD600 $=1.937$ was reached, which represented a concentration of $9.69 \times 108$ cells $/ \mathrm{mL}$. Afterwards, a $1 \mu \mathrm{L}$-aliquot of the starter culture was inoculated into $50 \mathrm{~mL}$ of the LB and Strep 100 medium and grown for $6.5 \mathrm{~h}$ to OD600 $=0.725$ (approximately $3.62 \times 108$ cell $/ \mathrm{mL}$ ). Subsequently, $50 \mu \mathrm{l}$-aliquots were aseptically distributed to 30 thin-walled PCR tubes (ProAmp PC7060, Alkali Scientific Inc., Pompano Beach, FL, USA) and kept on ice until used. These PCR tubes with K. oxytoca cultures, which were designated "biosensors," were employed as biologically-based sensors of thermal stress and were used to test the effectiveness of the steam treatments. The hinges of the PCR tubes were threaded with string, which was further threaded through an opening made in the bottom of an inverted small plastic cup (Dixie, Atlanta, GA, USA), thus creating a bell-like structure with the PCR tube hanging inside as the bell's clapper (as shown in Figure 2). Cups were necessary to protect biosensors from direct exposure to sunlight. The culture in PCR tube 1 was immediately plated as a control on a solid LB and Strep 100 agar with 3 replicates per dilution from $10^{-1}$ to $10^{-6}$ and incubated in a stationary incubator overnight $(\mathrm{ON})$ at $37^{\circ} \mathrm{C}$. Prior to the experiment, PCR tubes 2-30 were transported on ice from Gainesville to the Southwest Research and Education Center, University of Florida. A control tube was placed as the environmental control on a tree that was in the vicinity of the target tree but not exposed to the steam treatment. Twenty-eight tubes (numbers 2-30) were split into two groups. Fourteen of these tubes were placed around the target tree at different locations within Zones 2 and 3 (Figure 2a,c) prior to steam treatment. The coordinates of the biosensors were measured considering the center of the tree trunk as the origin of coordinates (Table 2). This experiment was repeated two times. Following the steam treatment, all PCR tubes were placed on ice, transported to the microbiology laboratory at the University of Florida, and serially diluted from $10^{-1}$ to $10^{-6}$. Five $\mu \mathrm{l}$-aliquots of each dilution were plated twice with 3 replicates each (a total of 6 spots per dilution) on a solid LB and Strep 100 medium and incubated in a stationary incubator $\mathrm{ON}$ at $37^{\circ} \mathrm{C}$. 
Table 2. Biosensor coordinates (center of trunk considered as the origin of coordinates).

\begin{tabular}{ccccc}
\hline & No. of Biosensor & \multicolumn{3}{c}{ Coordinate $(\mathbf{c m})$} \\
\cline { 3 - 5 } & & $x$ & $y$ & $z$ \\
\hline \multirow{3}{*}{ Zone 2 } & 1 & -60 & -30 & 94 \\
& 3 & 0 & 0 & 94 \\
& 4 & 66 & 0 & 90 \\
& 5 & -20 & -90 & 107 \\
& 6 & 54 & 15 & 174 \\
& 7 & 0 & -107 & 175 \\
& 8 & -116 & 0 & 94 \\
\hline & 9 & -38 & -45 & 100 \\
& 10 & -110 & -20 & 176 \\
& 11 & -110 & -20 & 190 \\
& 12 & -50 & 62 & 90 \\
& 13 & 25 & 0 & 95 \\
& 14 & 17 & -35 & 190 \\
& & -43 & 36 & 107 \\
\hline
\end{tabular}

After $24 \mathrm{~h}$, colonies were counted to determine survivability. The survival ratio was measured by the ratio of colony forming unites (CFU) of sample $\left(n_{t}\right)$ per the filed control (FC) sample $\left(n_{0}\right)$ (Equations (1) and (2)). The relationship between treatment temperatures and survival rate was studied too.

$$
\begin{gathered}
C F U(n)=\text { Average of three repeitions } \times \text { Dilution } \\
\text { Survival ratio }(S)=\frac{\text { sample } C F U}{\text { field control } C F U}=\frac{n_{t}}{n_{0}}
\end{gathered}
$$

\subsection{Experimental Design}

The effectiveness of the thermotherapy was evaluated on an HLB-affected citrus tree (Table 3). The experiment measured the pattern uniformity of heat distribution. The MHTS was used in order to artificially raise the temperature around and throughout the aerial portion of the HLB-affected target tree up to $54^{\circ} \mathrm{C}$ and then maintain this temperature in the canopy for about $90 \mathrm{~s}$.

Table 3. Target tree characteristics.

\begin{tabular}{cc}
\hline Variety & Hamlin \\
\hline Species & Citrus Sinensis \\
Origin & Florida, USA \\
Age & 6 years \\
Average size & $2.3 \mathrm{~m}$ height $\times 2$ m width \\
Disease & HLB $($ Citrus Greening) \\
Location & $26.4608^{\circ} \mathrm{N}, 81.4359^{\circ} \mathrm{W}$ \\
\hline
\end{tabular}

The target tree for this experiment was located at the experimental orchard of the Southwest Florida Research and Education Center of University of Florida, (Location: $26.4608^{\circ} \mathrm{N}, 81.4359^{\circ} \mathrm{W}$ ). To minimize the impact of other parameters such as tree height, canopy density and location, the test was repeated three times consecutively on the same target tree. The environmental temperature was, on average, $30{ }^{\circ} \mathrm{C}$ during the experiment. Environmental conditions changed very little between experiments since all replicates were conducted from 2 to 5 p.m. on the same day (5 June 2018). The average of humidity was $80 \%$, and the maximum and minimum temperatures were 36 and $28^{\circ} \mathrm{C}$, respectively. The temperature was recorded in three zones of the canopy and analyzed to evaluate the time course of heat increase and the profile of heat distribution [27]. A 3D graph of temperature and survival ratios were developed using nearest neighbor interpolation in MATLAB processing language. 


\section{Results and Discussion}

\subsection{Heat Distribution and Uniformity During Treatment}

Three experiments/repetitions were conducted to evaluate the mobile thermotherapy system. Table 4 shows the time which was taken to reach the temperature of $54{ }^{\circ} \mathrm{C}$ for each repetition. In addition, the temperature in three selected groups of sensors were presented. Figure 3 presents the temperature inside the canopy cover for different zones. Table 4 and Figure 3 indicate that the temperature difference in canopy and trunk was approximately $4{ }^{\circ} \mathrm{C}$, with the canopy temperature was being higher than the trunk. The average time to reach the desired temperature of $54{ }^{\circ} \mathrm{C}$ was $252 \mathrm{~s}$.

a.

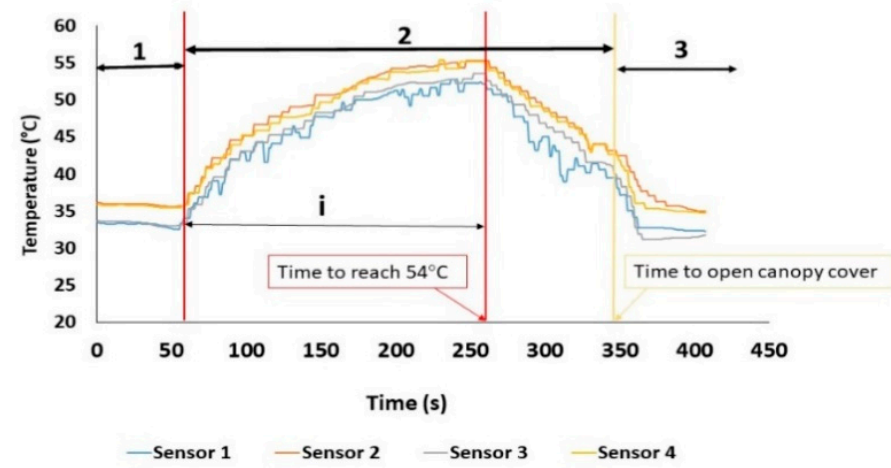

b.
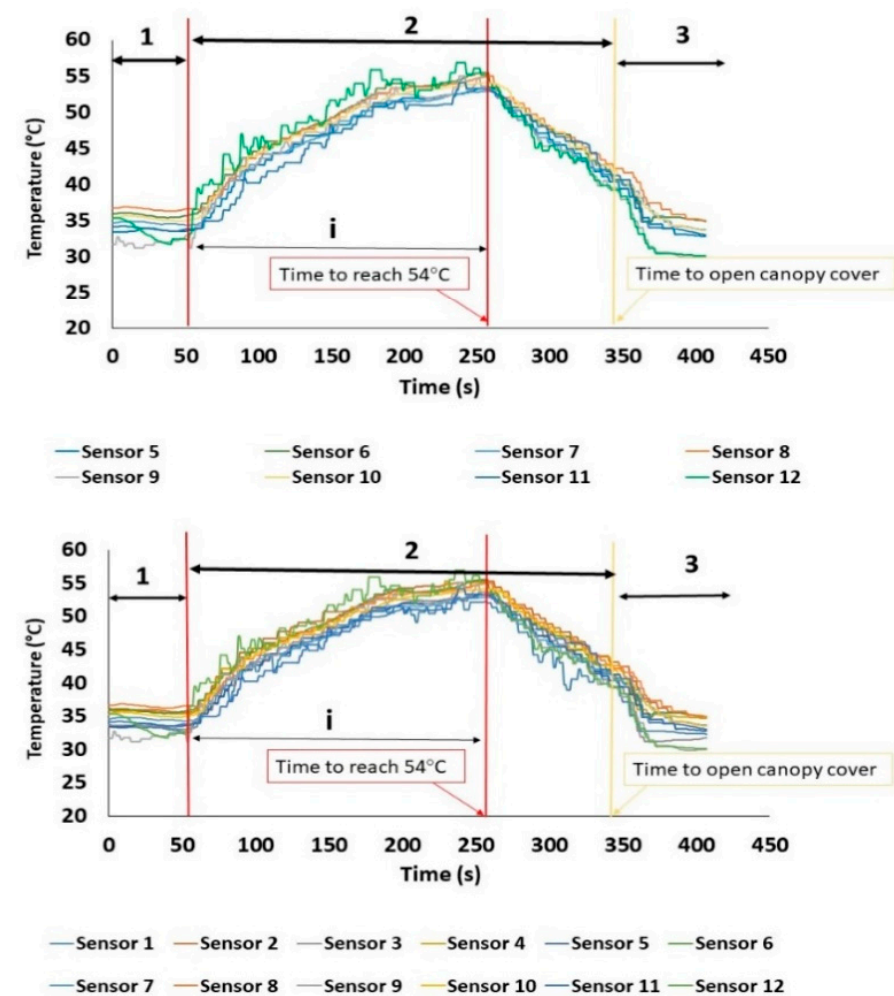

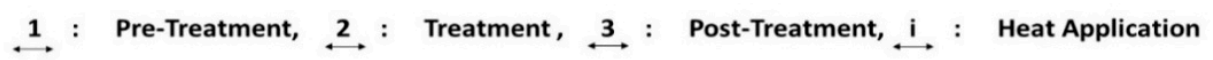

Figure 3. Temperature alterations inside the canopy cover during the steam treatment of Repetition 1.2, a. Zone 1, Trunk (Sensors 1-4); b. Zones 2 and 3, Canopy (Sensors 5-12); and c. Zone 1, 2 and 3, entire tree (Sensors 1-12). 
Table 4. Time to reach the desired temperature* of $54{ }^{\circ} \mathrm{C}$ for treatment.

\begin{tabular}{cccccccc}
\hline \multirow{2}{*}{$\begin{array}{c}\text { Experiment } \\
\text { No. }{ }^{* *}\end{array}$} & \multirow{2}{*}{ Time (s) } & \multicolumn{2}{c}{ Trunk (Zone 1) } & \multicolumn{2}{c}{ Canopy (Zones 2 and 3) } & \multicolumn{2}{c}{ Tree (Zones 1-3) } \\
\cline { 2 - 7 } & & Temperature $\left({ }^{\circ} \mathbf{C}\right)$ & SD & Temperature $\left({ }^{\circ} \mathbf{C}\right)$ & SD & Temperature $\left({ }^{\circ} \mathbf{C}\right)$ & SD \\
\hline 1.1 & 252.0 & 50.57 & 1.81 & 54.30 & 1.18 & 54.22 & 1.09 \\
1.2 & 257.0 & 51.40 & 1.31 & 53.97 & 1.21 & 53.92 & 1.05 \\
1.3 & 246.0 & 50.00 & 1.45 & 53.81 & 1.19 & 53.68 & 1.15 \\
Average & 251.6 & 50.65 & & 54.03 & & 53.94 & \\
\hline
\end{tabular}

* The presented temperature for each experiment is the mean of three replications, and the SD is the standard deviation of measured temperature in three experiments. ${ }^{* *}$ Experiment numbers 1.1 and 1.2 were performed with the use of biosensor packets.

Though the trend on increasing temperature per unit time was similar for all repetitions, each repetition had a different starting point of the "treatment" step; thus, using the average does not reflect an accurate result (i.e., since more time was required to reach the desired temperature of $54{ }^{\circ} \mathrm{C}$ in Repetitions 1.1 and 1.2 than in 1.3). Repetition 1.2 was chosen as a representative case study for treatment to be analyzed in detail and is presented in Figure 3.

Figure $3 \mathrm{a}$ shows the temperature recorded by Thermocouples 1-4 at Zone 1 (indicated as Sensors 1-4). Figure 3b presents the recorded canopy temperature (Sensors 5-12, Zones 2 and 3). The temperature for the whole tree is presented in Figure 3c (Sensors 1-12, all zones). The average time interval for the temperature within the whole canopy to reach the target temperature was $257 \mathrm{~s}$, while the area around the leaves and branches of the canopy reached that point in $252 \mathrm{~s}$, and the trunk area reached the target temperature in $256 \mathrm{~s}$. This is because of the upward convection of steam facilitated canopy heating faster than the trunk.

Figure 4 presents the 3D temperature distribution profile inside the canopy cover at 50, 120, 200, 220, 250, 300, and $350 \mathrm{~s}$ during heat treatment. These data show that heat distribution underneath the canopy cover was relatively uniform. As time passed, the heat distribution became slightly less uniform (Figure $4 \mathrm{c}-\mathrm{g}$ ); the truck sidewall neighborhood heated up at a slower rate in contrast to the side further away (Figure 4c-g).

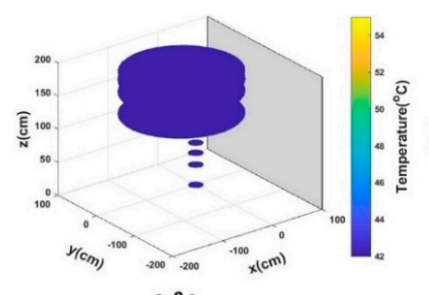

a. 0

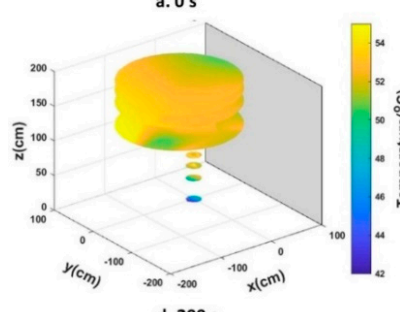

d. $200 \mathrm{~s}$

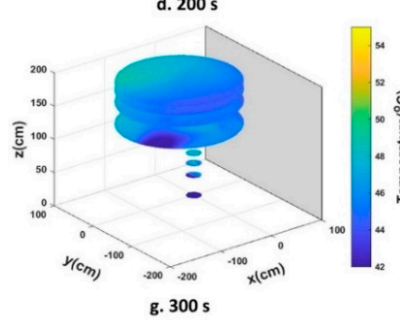

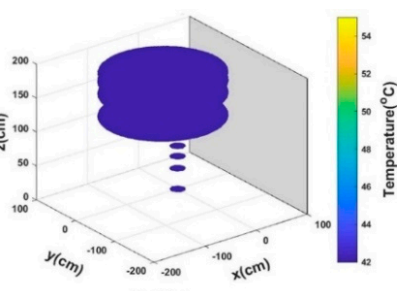

b. $50 \mathrm{~s}$

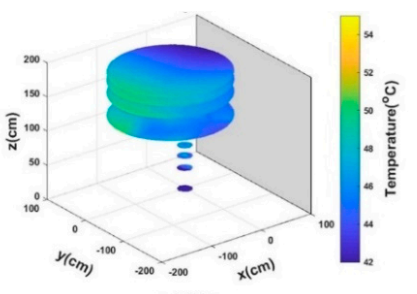

c. $120 \mathrm{~s}$
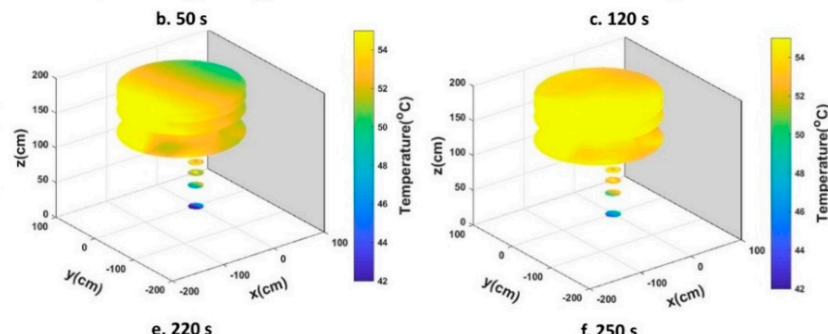

e. $220 \mathrm{~s}$

f. $250 \mathrm{~s}$

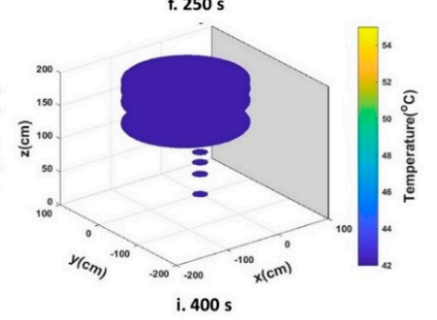

Figure 4. 3D graph of temperature distribution during heat treatment of diseased tree through the pre-treatment (a), treatment $(\mathbf{b}-\mathbf{g})$ and post treatment (h and $\mathbf{i})$ (Repetition 1.2). 
The area closer to the fans in the upper back portion of the canopy cover showed a lower temperature, as expected. Eight steam nozzles were distributed evenly throughout the canopy cover [27]; however, the shape and variable density of the tree canopy significantly affected the pattern of heat distribution, since it was asymmetric, causing heat to travel with varying efficiencies in different directions. At the end of the steam application phase (Figure $4 \mathrm{f}$ ), the temperature of the tree canopy furthest away from the truck sidewall was slightly higher. The gray plane in the 3D graph (Figure 4) represents the truck sidewall where the fans were installed.

In general, regions within the canopy near the truck tended to have a slightly lower temperature. There was greater air convection in this region, which hindered newly introduced steam from the nozzles from traveling in a direction counter to the airflow. As a consequence, more distal regions of the canopy hood over the course of the heating experienced the highest temperatures (yellow color), as expected [27]. Though slight non uniformity was observed in the temperature profiles during the course of heating, at the end of the treatment phase, temperatures varied no more than $2-3^{\circ} \mathrm{C}$ between the various canopy locations.

\subsection{Biosensors Survival Rate after Heat Treatment}

Equal aliquots of the K. oxytoca culture were dispensed into the biosensor PCR tubes, and an additional aliquot was taken for determination of the starting cell numbers. The biosensor cultures were shielded from convection by the walls of the plastic cup, whereas the thermocouples were directly exposed. Ten-fold serial dilutions were plated on LB Strep 100 agar plates and incubated at $37^{\circ} \mathrm{C}$ for $24 \mathrm{~h}$ for colony growth after the heat treatments. Survivability (S) ratios $\left(\mathrm{n}_{\mathrm{t}} / \mathrm{n}_{0}\right)$ were calculated as a ratio of the number of colony forming units after treatment divided by the number in the field control (FC). A log of the survivability ratio provides a way to access the killing efficiency of the treatment with, as a comparison, a reduction of five logs being recommended for bacterial contamination of alfalfa seeds by the U. S. Food and Drug Administration [31]. The survivability ratios are reported in Table 5 and range from a log reduction of -3.35 to complete killing. The 3D graph of $K$. oxytoca biosensor survivability after the heat treatment is shown in Figure 5. The dark blue color on the graph indicates the lowest bacterial survival percentage, while the yellow reveals the higher percentage of biosensor survivability. The best eradication of the bacteria happened in the area closer to the truck sidewall of the tree canopy, while the opposite side allowed for some bacterial growth. The accumulated temperature during all treatment steps and the survival ratio of each biosensor are shown in Figure 6. The lack of a direct correlation between survivability and the thermal profile is not surprising since the thermocouples were not colocalized with the biosensors.

Table 5. Survivability ratio of Klebsiella oxytoca biosensors after treatment.

\begin{tabular}{|c|c|c|c|c|c|c|c|}
\hline Biosensor Sample No. & $\begin{array}{c}\text { Survival } \\
\text { Ratio }\end{array}$ & $\log S\left(\frac{n_{t}}{n_{0}}\right)$ & $\begin{array}{c}\text { Cell } \\
\text { Number }\end{array}$ & $\begin{array}{c}\text { Colonies } \\
\text { (Rep 1) }\end{array}$ & $\begin{array}{c}\text { Colonies } \\
\text { (Rep 2) }\end{array}$ & $\begin{array}{c}\text { Colonies } \\
\text { (Rep 3) }\end{array}$ & Dilution \\
\hline LC (Lab control) & & & $1.33 \times 10^{6}$ & 12 & 11 & 17 & $1.00 \times 10^{5}$ \\
\hline FC (Field control) & 100 & & $2.47 \times 10^{6}$ & 29 & 26 & 19 & $1.00 \times 10^{5}$ \\
\hline 1 & 0.0091 & -4.04 & $2.23 \times 10^{2}$ & 28 & 18 & 21 & $1.00 \times 10^{1}$ \\
\hline 2 & 0.0000 & killed & $0.00 \times 10^{0}$ & 0 & 0 & 0 & $1.00 \times 10^{1}$ \\
\hline 3 & 0.0004 & -5.39 & $1.00 \times 10^{1}$ & 1 & 1 & 1 & $1.00 \times 10^{1}$ \\
\hline 4 & 0.0004 & -5.39 & $1.00 \times 10^{1}$ & 0 & 0 & 3 & $1.00 \times 10^{1}$ \\
\hline 5 & 0.0000 & killed & $0.00 \times 10^{0}$ & 0 & 0 & 0 & $1.00 \times 10^{1}$ \\
\hline 6 & 0.0000 & killed & $0.00 \times 10^{0}$ & 0 & 0 & 0 & $1.00 \times 10^{1}$ \\
\hline 7 & 0.0446 & -3.35 & $1.10 \times 10^{3}$ & 12 & 11 & 10 & $1.00 \times 10^{1}$ \\
\hline 8 & 0.0001 & -5.87 & $3.33 \times 10^{0}$ & 0 & 0 & 1 & $1.00 \times 10^{1}$ \\
\hline 9 & 0.0000 & killed & $0.00 \times 10^{0}$ & 0 & 0 & 0 & $1.00 \times 10^{1}$ \\
\hline 10 & 0.0000 & killed & $0.00 \times 10^{0}$ & 0 & 0 & 0 & $1.00 \times 10^{1}$ \\
\hline 11 & 0.0008 & -5.09 & $2.00 \times 10^{2}$ & 0 & 4 & 2 & $1.00 \times 10^{1}$ \\
\hline 12 & 0.0446 & -3.35 & $1.10 \times 10^{3}$ & 9 & 10 & 14 & $1.00 \times 10^{2}$ \\
\hline 13 & 0.0005 & -5.27 & $1.33 \times 10^{1}$ & 2 & 2 & 0 & $1.00 \times 10^{1}$ \\
\hline 14 & 0.0014 & -4.87 & $3.33 \times 10^{1}$ & 1 & 5 & 4 & $1.00 \times 10^{1}$ \\
\hline
\end{tabular}




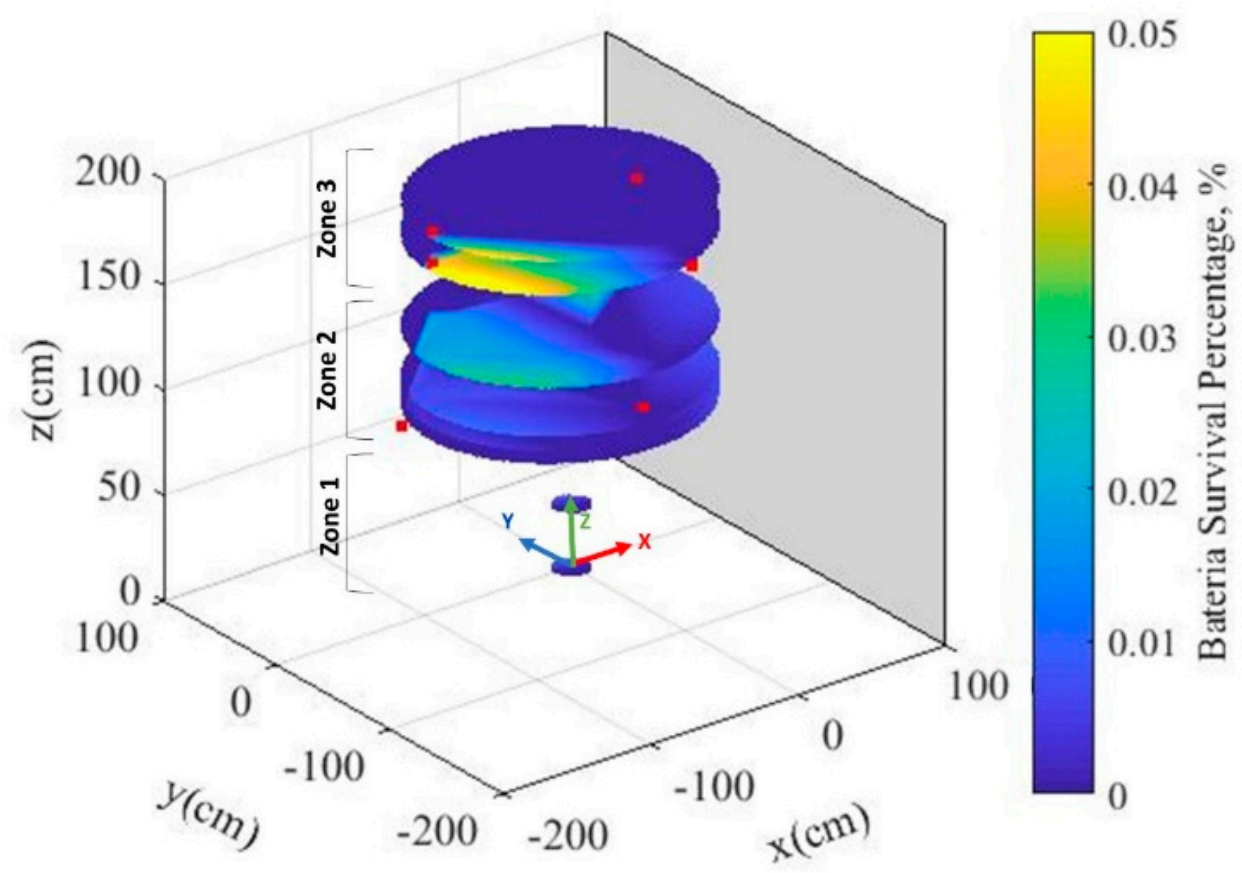

Figure 5. 3D graph of biosensor survival rate based on the locations within the canopy on the target tree (red dots indicate visible biosensors).

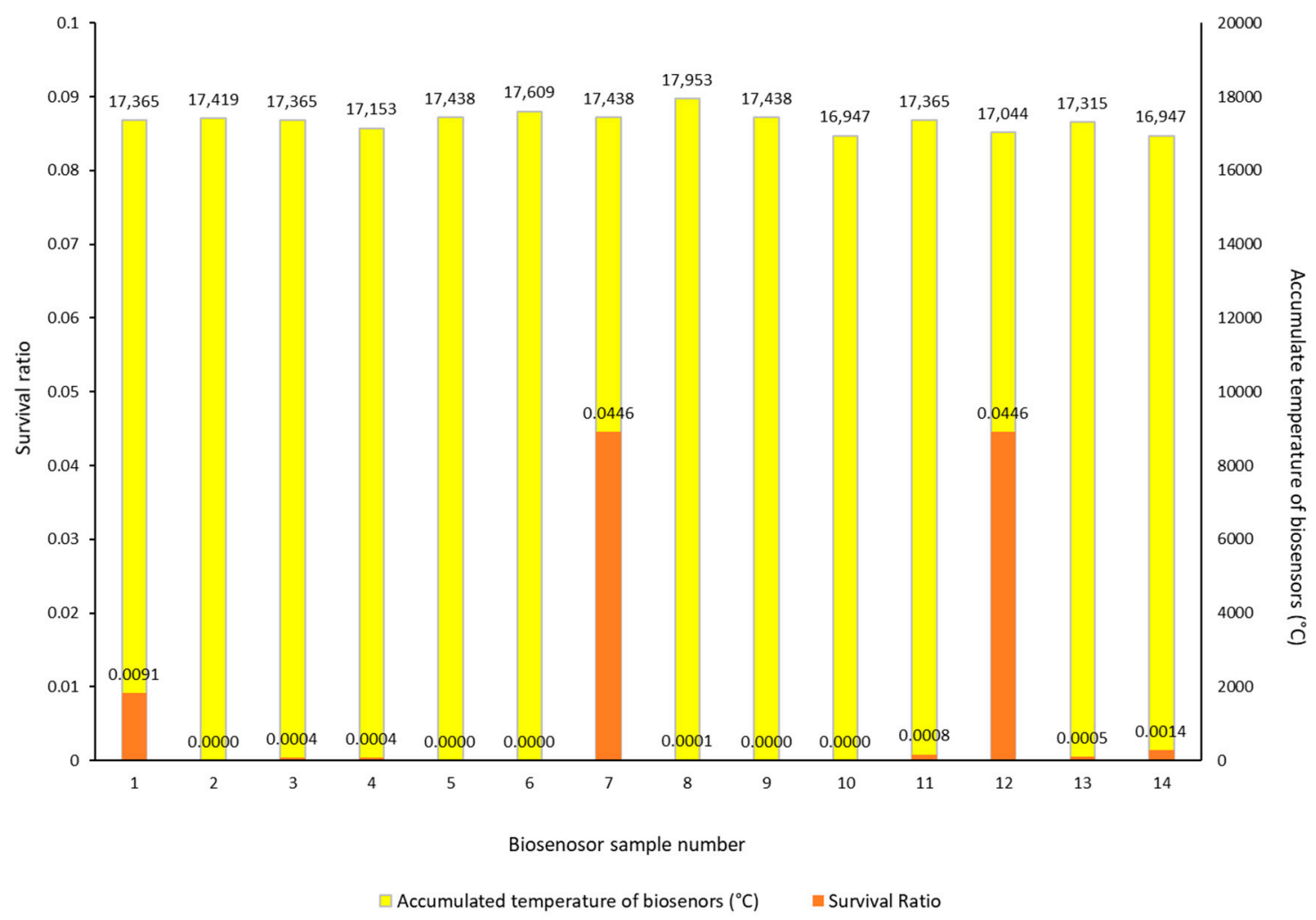

Figure 6. Accumulated temperature and survival ratio of biosensors during the entire treatment process (400 s).

\section{Conclusions}

A mobile heat treatment system was evaluated in the field by using a biologically-based sensor. The pattern of heat distribution was monitored inside the canopy cover and presented as a 3D graph. 
These results indicate that the heat distribution underneath the canopy cover was generally uniform, while the temperature of the tree canopy was higher than the tree trunk area. Some of the factors that affected the temperature distribution and uniformity were the number and location of nozzles, the shape of the canopy cover, and fan characteristics. The efficacy of the heat treatment system to kill K. oxytoca bacteria was analyzed by measuring the survivability ratio of the biosensor cultures. These bacteria are sensitive to the low and medium levels of heat. Our results indicated that the killing efficiencies of the heat treatment ranged from $3.35 \mathrm{log}$ reductions in colony forming units to the complete elimination of the bacteria. Most of the biosensors were placed near the outer edge of the tree canopy, a location of high temperature and effective killing of the surrogate bacteria. Though temperatures were generally uniform, and the killing efficiencies of the heat treatment were generally good, there was no tight correlation at the microscale level between measured temperatures and survivability. Also, there was no logical correlation between accumulated temperature and survival ration of each biosensors. The lack of colocalization of thermocouples with biosensors and differences heat accessibility between the two apparatuses probably account for these apparent discrepancies. To more accurately evaluate the in-field heat treatment system, our future work will focus on measuring the temperature and heat penetration inside the tree and into the phloem where the CLas bacteria live.

Author Contributions: Conceptualization, E.C., W.B.G., and Y.A.; methodology, S.G., E.C., W.B.G., and Y.A.; validation, S.G., E.C., F.L.V., W.B.G., and Y.A.; formal analysis, S.G., F.L.V., and W.B.G.; investigation, S.G., E.C., F.L.V., W.B.G., and Y.A.; resources, R.E., E.C., W.B.G., and Y.A.; data curation, S.G., E.C., F.L.V., W.B.G., and Y.A.; writing-original draft preparation, S.G., E.C., and W.B.G.; writing-review and editing, E.C., W.B.G., R.E., and Y.A.; visualization, S.G., E.C., and W.B.G.; supervision, E.C., W.B.G., and Y.A.; project administration, W.B.G., and Y.A.; funding acquisition, R.E., W.B.G., and Y.A.

Funding: This work was supported by the USDA/NIFA award \#2015-70016-23030. Statements in this document do not reflect the position or policy of the USDA.

Conflicts of Interest: The authors declare no conflict of interest.

\section{References}

1. Grondeau, C.; Samson, R.; Sands, D.C. A Review of Thermotherapy to Free Plant Materials from Pathogens, Especially Seeds from Bacteria. Crit. Rev. Plant Sci. 1994, 13, 57-75. [CrossRef]

2. Hoffman, M.T.; Doud, M.S.; Williams, L.; Zhang, M.-Q.; Ding, F.; Stover, E.; Hall, D.; Zhang, S.; Jones, L.; Gooch, M.; et al. Heat Treatment Eliminates 'Candidatus Liberibacter asiaticus' from Infected Citrus Trees Under Controlled Conditions. Am. Phytopathol. Soc. 2013, 103, 15-22. [CrossRef] [PubMed]

3. Sands, D.C.; Fourest, E.; Rehms, L.D. Dry heat seed treatment for Xanthomonas campestris pv. Translucens. In Proceedings of the 7th International Conference on Plant Pathogenic Bacteria, Budapest, Hungary, 11-16 June 1989; Klement, Z., Ed.; AkademiaiKiado: Budapest, Hungary, 1989.

4. Kunkel, L.O. Heat treatment for the control of yellows and other virus diseases of peach. Phytopathology 1936, 26, 809-830.

5. Grant, T.J. Heat treatments for obtaining sources of virus-free citrus budwood. Fla. State Hortic. Soc. 1957, 70, 51-53.

6. Grant, T.J.; Jones, J.W.; Norman, G.C. Present status of heat treatment of citrus viruses. Fla. State Hortic. Soc. 1959, 72, 45-48.

7. Nyland, G.; Goheen, A.C. Heat therapy of virus diseases of perennial plants. Annu. Rev. Phytopathol. 1969, 7, 331-354. [CrossRef]

8. Verma, J.P.; Nayak, M.L.; Singh, R.P. Elimination of Xanthomonas malvacearum from cotton seeds by hot water. Indian Phytopathol. 1978, 30, 73-76.

9. Leben, C. Chemical plus heat as seed treatments for control of angular leaf spot of cucumber seedlings. Plant Dis. 1983, 65, 991-993. [CrossRef]

10. Shekhawat, G.S.; Srivastava, D.N. Control of bacterial leafleafstreak of rice (Oryza sativa L.). Indian J. Agric. Sci. 1971, 41, 1098-1101.

11. Devash, Y.; Okon, Y.; Henis, Y. Survival of Pseudomonas tomato in Soil and Seeds. J. Phytopathol. 1980, 99, 175-185. [CrossRef] 
12. Hankin, L. Microwave Treatment of Tobacco Seed to Eliminate Bacteria on the Seed Surface. Phytopathology 1977, 77, 794-795. [CrossRef]

13. Hoy, J.W.; Flynn, J.L. Control of ratoon stunting disease of sugarcane in Louisiana with seedcane produced through micropropagation and resistant cultivars. Int. Soc. Sugar Cane Technol. 2001, 24, 417-421.

14. Damann, K.E.J.; Benda, G.T.A. Evaluation of commercial heat-treatment methods for control of ratoon stunting disease of sugarcane. Plant Dis. 1983, 67, 966-967. [CrossRef]

15. Viswanathan, R. Different aerated steam therapy (AST) regimes on the development of grassy shoot disease symptoms in sugarcane. Sugar Tech. 2001, 3, 83-91. [CrossRef]

16. Arioli, S.; Montanari, C.; Magnani, M.; Tabanelli, G.; Patrignani, F.; Lanciotti, R.; Mora, D.; Gardini, F. Modelling of Listeria monocytogenes Scott A after a mild heat treatment in the presence of thymol and carvacrol: Effects on culturability and viability. J. Food Eng. 2019, 240, 73-82. [CrossRef]

17. Hong, E.; Park, S.; Kang, D. Sequential treatment of hydrogen peroxide, vacuum packaging, and dry heat for inactivating Salmonella Typhimurium on alfalfa seeds without detrimental effect on seeds viability. Food Microbiol. 2019, 77, 130-136. [CrossRef]

18. Hussain, M.S.; Tango, C.N.; Oh, D.H. Inactivation kinetics of slightly acidic electrolyzed water combined with benzalkonium chloride and mild heat treatment on vegetative cells, spores, and biofilms of Bacillus cereus. Food Res. Int. 2019, 116, 157-167. [CrossRef]

19. Kirk, J.A.; Fagan, R.P. Heat shock increases conjugation efficiency in Clostridium difficile. Anaerobe 2016, 42, 1-5. [CrossRef]

20. Sharma, S.L.; Varma, A. Cure of seed transmitted cowpea banding mosaic virus. Phytopathol. Z. 1975, 83, 144-151. [CrossRef]

21. Gottwald, T.R. Citrus Canker and Citrus Huanglongbing, two Exotic Bacterial Diseases Threatening the Citrus Industries of the Western Hemisphere. Outlooks Pest Manag. 2007, 18, 274-279. [CrossRef]

22. Lopes, S.A.; Frare, G.F. Liberibacters Associated with Citrus Huanglongbing in Brazil: 'Candidatus Liberibacter asiaticus' Is Heat Tolerant, 'Ca. L. americanus' Is Heat Sensitive. Plant Dis. 2009, 93, 257-262. [CrossRef]

23. Lin, K.H.; Zheng, R.Y. A preliminary study on citrus yellow shoot disease virus and resistance of the diseased citrus budwood to heat. Acta Phytopathol. Sin. 1964, 4, 169-174.

24. Fan, G.-C.; Xia, Y.-L.; Lin, X.-J.; Hu, H.-Q.; Wang, X.-D.; Ruan, C.-Q.; Lu, L.-M.; Liu, B. Evaluation of thermotherapy against Huanglongbing (citrus greening) in the greenhouse. J. Integr. Agric. 2016, 15, 111-119. [CrossRef]

25. Doud, A.; Wang, Y.; Hoffman, M.T.; Latza, C.L.; Luo, W.; Armstrong, C.M.; Gottwald, T.R.; Dai, L.; Luo, F.; Duan, Y. Solar thermotherapy reduces the titer of Candidatus Liberibacter asiaticus and enhances canopy growth by altering gene expression profiles in HLB-affected citrus plants. Hortic. Res. 2017, 4, 17054. [CrossRef]

26. Abdulridha, J.; Ampatzidis, Y.; Ghatrehsamani, S.; Ehsani, R. Mobile thermotherapy system for treating HLB-infected citrus trees utilizing hot water and steam. In Proceedings of the 2018 ASABE Annual International Meeting (ASABE AIM), Detroit, MI, USA, 29 July-1 August 2018.

27. Ghatrehsamani, S.; Abdulridha, J.; Balafoutis, A.; Zhang, X.; Ehsani, R.; Ampatzidis, Y. Development and evaluation of a mobile thermotherapy technology for in-field treatment of Huanglongbing (HLB) affected trees. Biosyst. Eng. 2019, 182, 1-15. [CrossRef]

28. European Association of National Metrology Institutes. Technical Committee for Thermometry, Calibration of Thermocouples; EURAMET: Berlin, Germany, 2011; pp. 1-19.

29. Wood, B.E.; Ingram, L.O. Ethanol Production from Cellobiose, Amorphous Cellulose, and Crystalline Celluloseby Recombinant Klebsiella oxytoca Containing Chromosomally Integrated Zymomonas mobilis Genes for Ethanol Production and Plasmids Expressing Thermostable Cellulase Genes from Clostridium thermocellumt. Appl. Environ. Microbiol. 1992, 58, 2103-2110.

30. Ohta, K.; Beall, D.S.; Mejia, J.P.; Shanmugam, K.T.; Ingram, L.O. Metabolic engineering of Klebsiella oxytoca M5A1 for ethanol production from xylose and glucose. Appl. Environ. Microbiol. 1991, 57, 2810-2815.

31. Guidance for Industry: Reducing Microbial Food Safety Hazards for Sprouted Seeds; C.U.S. Food and Drug Administration: Silver Spring, MD, USA, 1999.

(C) 2019 by the authors. Licensee MDPI, Basel, Switzerland. This article is an open access article distributed under the terms and conditions of the Creative Commons Attribution (CC BY) license (http://creativecommons.org/licenses/by/4.0/). 